Case Report

\title{
Right Transverse Testicular Ectopia: A Nonclassified Variant Confirmed on Laparoscopy
}

\author{
Landry Mbouché $\mathbb{D}^{1,2}$ E. Njuma Tamufor, ${ }^{1}$ K. G. Fossi, ${ }^{1}$ A. S. Salihou, ${ }^{1}$ D. E. C. Dikongue, ${ }^{1}$ \\ Salihou Fadi, ${ }^{1}$ Bienvenu Binwe, ${ }^{1}$ and F. F. Mouafo Tambo ${ }^{1,2}$ \\ ${ }^{1}$ Faculty of Medicine and Biomedical Sciences, University of Yaounde I, Cameroon \\ ${ }^{2}$ Yaounde Gynaeco-Obstetric and Paediatric Hospital, Cameroon \\ Correspondence should be addressed to Landry Mbouché; landrymbouche@gmail.com
}

Received 29 June 2021; Accepted 22 September 2021; Published 8 October 2021

Academic Editor: Walid Farhat

Copyright (c) 2021 Landry Mbouché et al. This is an open access article distributed under the Creative Commons Attribution License, which permits unrestricted use, distribution, and reproduction in any medium, provided the original work is properly cited.

\begin{abstract}
Transverse testicular ectopia is a rare anomaly characterized by testicular descent into the scrotum through the same inguinal canal. Here, we report the case of a 15-year-old boy diagnosed with transverse testicular ectopia wherein both testes descended through separate inguinal canals. He underwent a diagnostic laparoscopy which helped to identify both spermatic cords entering both inguinal canals separately. During scrotal exploration, both testes were found in the same side. Transseptal orchidopexy was performed. The short-term follow-up is uneventful.
\end{abstract}

\section{Introduction}

Ectopic testis is the migration of the testis away from its normal route of descent. The common sites for ectopic testes include the superficial inguinal pouch, femoral canal, perineum, pubopenile region, and opposite scrotum and is also called transverse testicular ectopia (TTE). The latter is a rare form of testicular ectopia wherein both testes descend along the same inguinal route and are found in the same hemiscrotum [1]. Following the first description by Von Lenhossek in 1886 [2], it has been reported in the literature in over a hundred cases as crossed testicular ectopia, pseudoduplication, unilateral double testes, transverse aberrant testicular maldescent, or transverse testicular ectopia [3] with patients' ages ranging from 3 days to 77 years [4]. These cases have been reported with various associated malformations. We present here the case of a 15-year-old boy with a transverse testicular ectopia. Laparoscopy and scrotal operation showed both spermatic cords entering their independent inguinal canals while the testes are located on the same side.

\section{Case Presentation}

We received a 15-year-old male at our outpatient consultation with complaints of an abnormal looking scrotum and a left scrotal swelling. He denied testicular pain. His past history was notable for the presence of this scrotal anomaly from birth with several consultations done in infancy and no definitive diagnosis nor management proposed. On examination, there was a vacant, hypoplastic right hemiscrotum with no palpable right testis along its normal course; a normal looking left hemiscrotum containing a testis; an ovoid shaped mass at the left suprascrotal area which was firm, nontender and not fixed to the deep or superficial plane (Figures 1 and 2). There was no hypogastric mass, no palpable kidney mass, and no disorder of sex development. The penis was uncircumcised.

An abdominal ultrasound found no renal anomalies, and description of the left suprapubic mass was inconclusive. A diagnostic laparoscopy was planned to explore the right testis and any anomaly. On laparoscopic evaluation under general anesthesia, the right spermatic vessels and vas were seen 

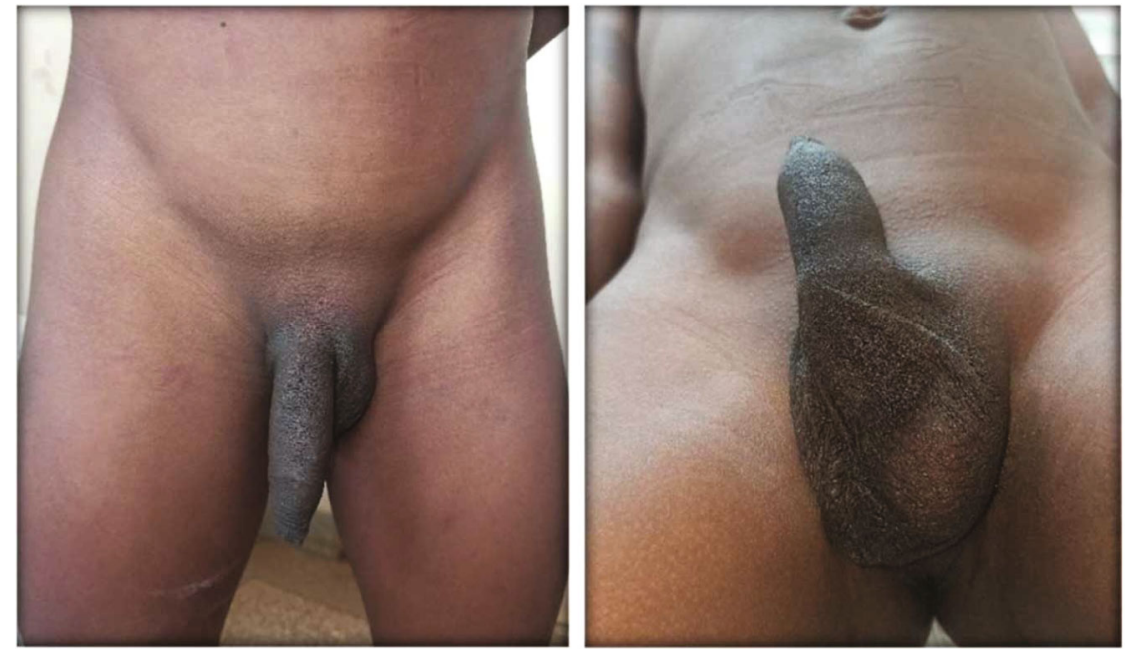

Figure 1: Patient in standing and lying positions showing hypoplasia of right hemiscrotum and left suprascrotal bulge.

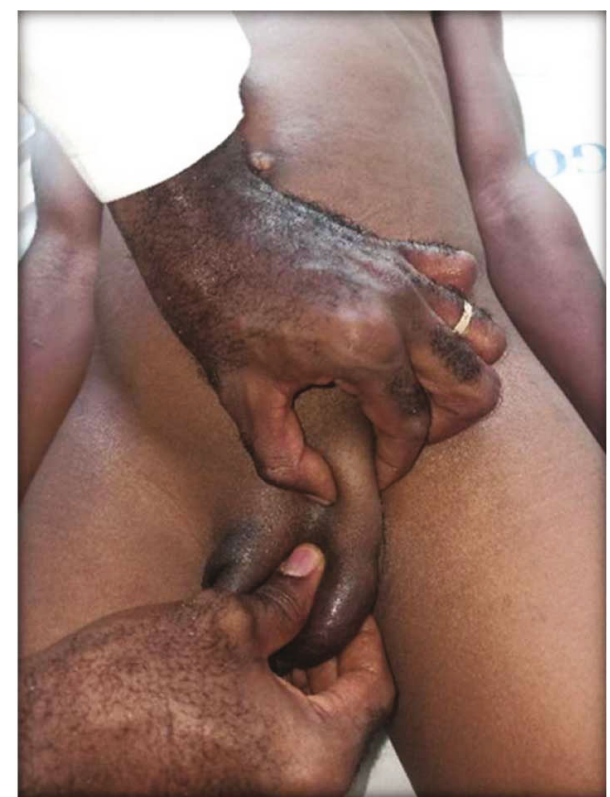

FIGURE 2: Examiner isolating two separate masses on the left path of testicular descent.

going through an open right deep inguinal ring (Figure 3). The spermatic vessels and vas on the left were seen traversing their corresponding closed deep inguinal ring (Figure 4). There were no Müllerian remnants. To identify the origin of the two left-sided scrotal masses during laparoscopy, the lowermost intrascrotal mass was tugged and the effect was seen at the right deep inguinal ring. Meanwhile, tugging of the higher-placed suprascrotal mass resulted in denting of the left deep inguinal ring structures with no effect on the right deep inguinal ring.

A scrototomy through a median raphe incision was made. The lowermost testis was easily dissected and its cord traced to the right side passing front of the root of the penis. The higher placed testis' dissection was more laborious with adhesions and an inflammatory tunica. Both testis appeared

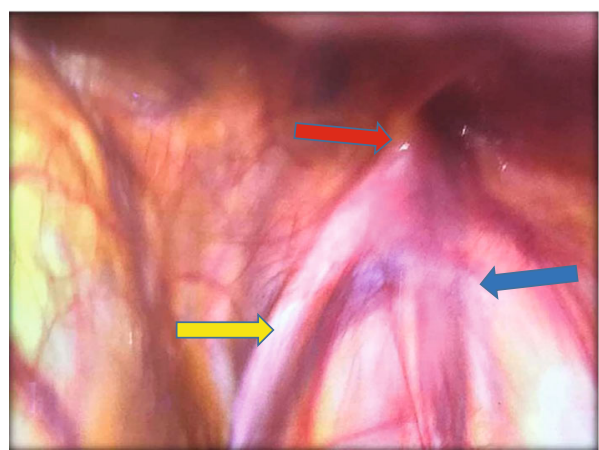

FIGURE 3: Laparoscopic view of the spermatic vessels (blue arrow) and vas deferens (yellow arrow) exiting the right "open" deep inguinal ring (red arrow).

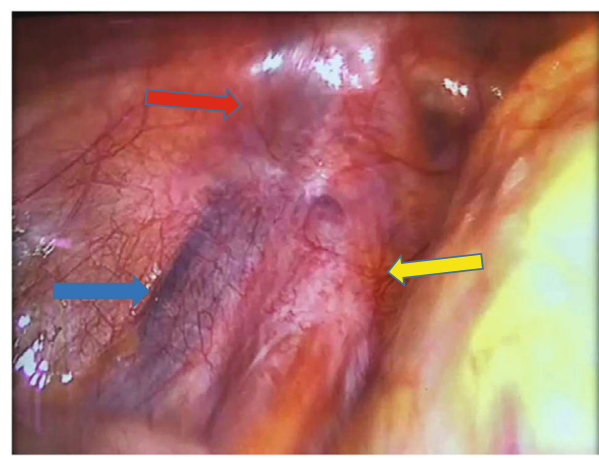

FIgURE 4: Laparoscopic view of the spermatic vessels (blue arrow) and vas deferens (yellow arrow) exiting the left "closed" deep inguinal ring (red arrow).

macroscopically normal with no epididymotesticular fusion anomaly and unfused vasa deferentia (Figure 5). A right inguinal exploration found a patent processus vaginalis which was transected and closed at the deep ring. Transseptal orchidopexy was undertaken for the right testis with its longer cord length (Figure 6), and an ipsilateral orchidopexy was done for the nondescended suprascrotal left testis 


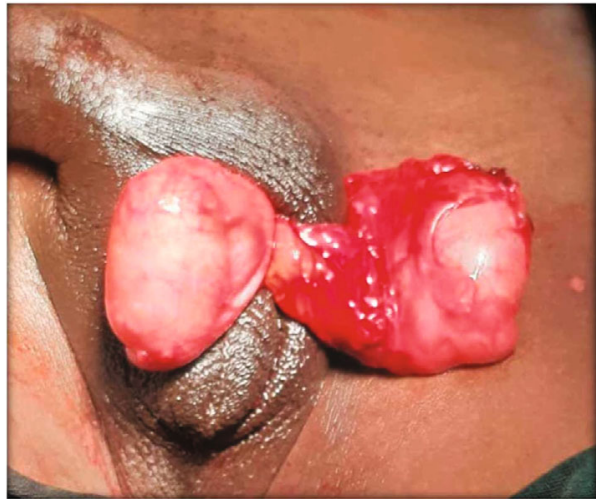

(a)

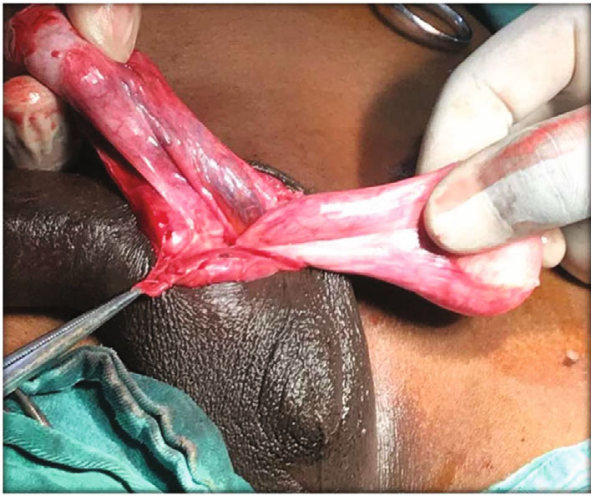

(b)

FIGURE 5: (a) Left and right testes shown through a median raphe scrototomy looking macroscopically normal. (b) No fusion of vessels nor vasa, nor epididymotesticular separation.

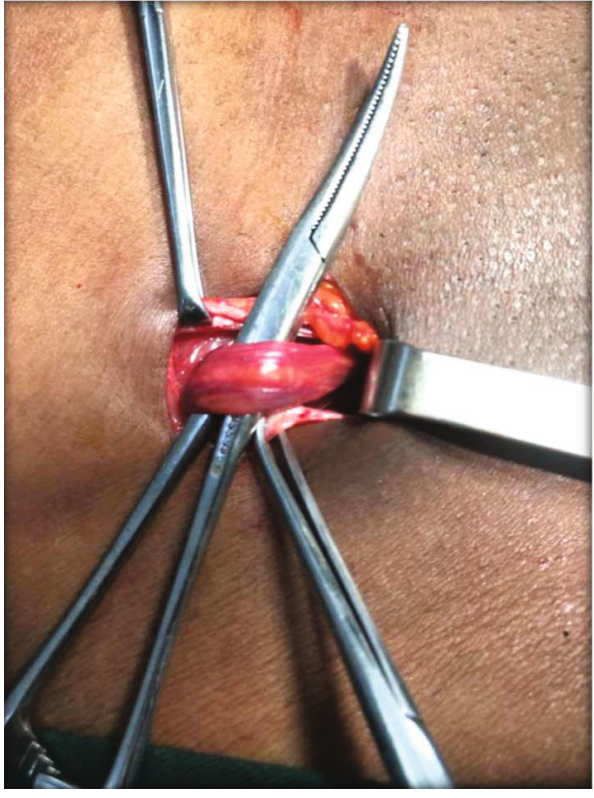

(a)

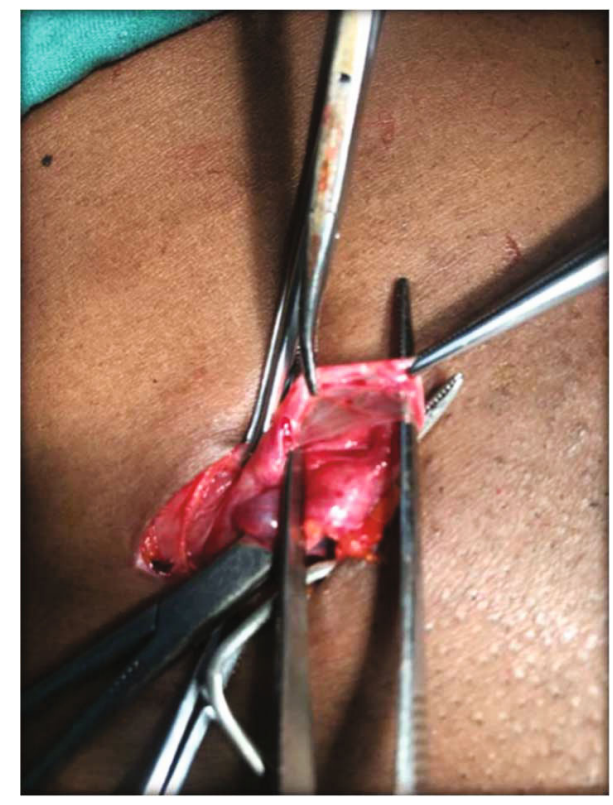

(b)

FIgURE 6: (a) Right inguinal dissection. (b) Closure of a right patent processus vaginalis.

(Figure 7). Circumcision was done. The early postoperative period was uneventful with mild tenderness on palpation and a full-looking scrotum (Figures 8 and 9).

\section{Discussion}

Some theories have been postulated to explain this singular anomaly of testicular descent which vary depending on the presentation and associated anomalies. A faulty development of both testes on the same side was proposed by Lenhossek and later Berg [5]. Kimura [6] concluded that if both vasa deferentia arose from one side, there had been unilateral origin but if there was bilateral origin, one testis had crossed over due to some compression force. Gupta and Das [7] postulated that adherence and fusion of the developing Wolffian ducts took place early and that descent of one testis caused the second one to follow. This has been referred to as mechanical hindrance by Chacko and colleagues [8]. Defective implantation of the gubernaculum or an obstruction of the inguinal canal preventing testicular descent on the ipsilateral side was confirmed on rat models [9]. The presence of Müllerian structures in persistent Müllerian duct syndrome (PMDS) may bind to vasa and affect their descent $[10,11]$.

The spectrum of associated clinical findings most commonly includes ipsilateral inguinal hernia, hypospadias, PMDS, disorder of sex differentiation (DSD), fusion of vas deferens, seminal vesicle cysts, renal agenesis, and scrotal abnormalities $[12,13]$. The classification proposed by Gauderer et al. [14] is based on the presence of associated abnormalities: Type 1, the most common type (40-50\%) is associated with ipsilateral inguinal hernia alone; Type 2 (30\%) is associated with persistent Müllerian duct structures; and Type $3(20 \%)$ is associated with other genitourinary 


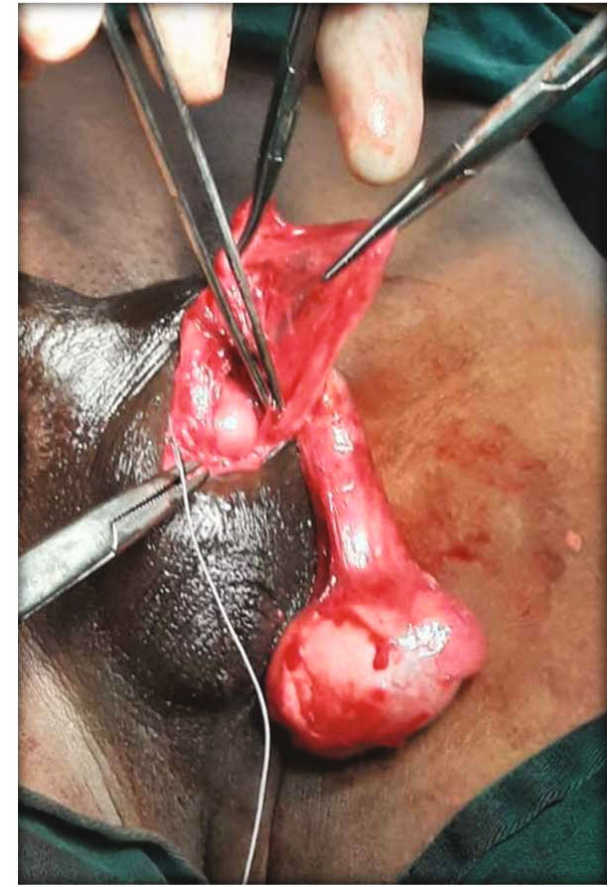

FIGURE 7: Transseptal orchidopexy of the right testis and closure of the scrotal septum.

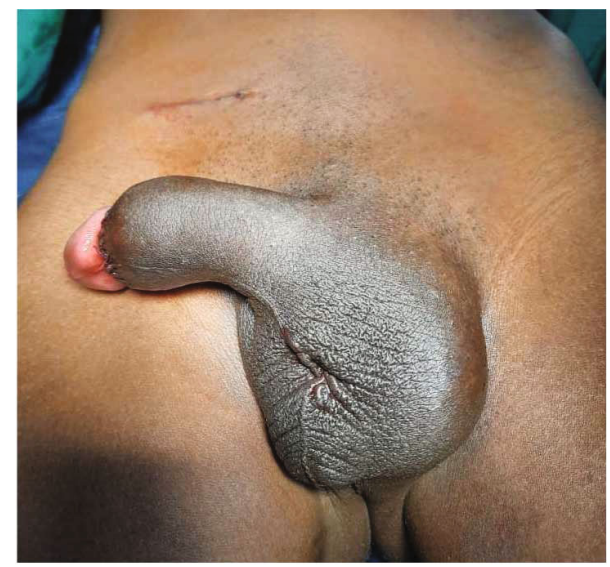

FIGURE 8: Final aspect after bilateral orchidopexy and routine circumcision.

abnormalities without Müllerian remnants. We present a form of TTE wherein the spermatic cords go through their individual inguinal canals to end up in the same hemiscrotum. In our case, the right testis probably reached the contralateral scrotum first and acted as an obstacle to the normal descent of the left testis into its scrotal sac. A similar anatomic configuration has been described previously involving the left testicle [1].

The diagnosis was confirmed by laparoscopic visualization of cord structures passing through their separate deep inguinal rings, respectively. The left internal inguinal ring was closed but the right deep inguinal ring was open. This underscores the importance of laparoscopic exploration as a diagnostic modality to investigate undescended nonpalp-

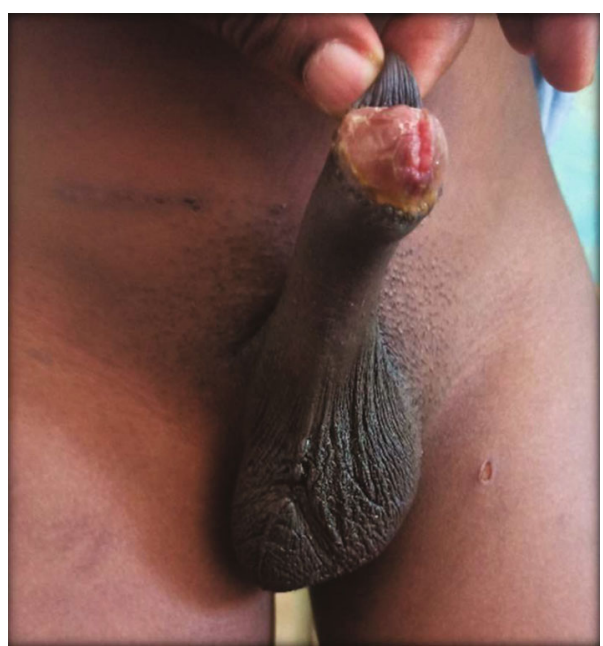

Figure 9: Scrotal aspect on day 5 postoperative.

able testes in place of other imaging like magnetic resonance imaging, ultrasonography, and computed tomography [15-17] which may describe some of the abnormalities associated with TTE.

The management goals are fixation of the testes, search for Müllerian duct remnants, and long-term follow-up for malignancy and fertility [18]. The overall incidence of malignant transformation of gonads is $18 \%$ [19]. There is no formal consensus on the management due to the rarity of the pathology and its varied presentation [20]. Nonetheless, algorithms based on extensive dissection of the cord [21] or none at all [22] have been proposed to guide management after intraoperative findings. Still, some authors advocate complete dissection to individualize the testes and spermatic cords with transseptal or extraperitoneal orchidopexy through an inguinal or scrotal approach [18]. Laparoscopic surgery with or without inguinal exploration has been described for management of TTE and associated anomalies in staged or single procedures [23, 24]. We used laparoscopy for diagnosis and then a scrotal approach to explore the left hemiscrotum and successfully placed both testes in separate scrotal compartments through a transseptal orchidopexy. There was no need for an ipsilateral inguinal incision because deep inguinal ring was closed on laparoscopic exploration. The follow-up will be ensured by regular examination of the testis through physical examination and ultrasound.

\section{Conclusion}

Nonpalpable testis in a child associated with contralateral full scrotum should lead to researching all potential sites of testicular ectopy. Laparoscopy should be privileged in the exploration as it can identify the paths of the different cords and avoid additional dissection. A new classification and consensus in the management of transverse testicular ectopy could be considered with regard to the variant form presented. In early or late presentation, a follow-up is warranted in terms of testicular size, functional status, and malignant transformation. 


\section{Consent}

Informed consent was obtained from the patient's guardian for publication of this case report.

\section{Conflicts of Interest}

The authors declare that there is no conflict of interest regarding the publication of this article.

\section{Acknowledgments}

We would like to acknowledge Dr He Guo Lin, from the Chinese Medical Team in the Yaounde Gynaeco-Obstetric and Paediatric Hospital, who participated in the laparoscopic exploration.

\section{References}

[1] L. Kumar, P. Garg, A. Kumar, and A. S. N. Rao, "Transverse testicular ectopia with bilateral pyocoele: case report and brief review of literature," Journal of Surgical Technique and Case Report, vol. 6, no. 2, pp. 55-57, 2014.

[2] M. N. Von Lenhossek, "Ectopia testis transversa," Anatomischer Anzeiger, vol. 1, pp. 376-381, 1886.

[3] S. Naouar, K. Maazoun, L. Sahnoun et al., "Transverse testicular ectopia: a three-case report and review of the literature," Urology, vol. 71, no. 6, pp. 1070-1073, 2008.

[4] P. Debnath, R. Tripathi, L. Agarwal, E. Malik, and S. Sharma, "Tuberculosis in transverse testicular ectopic testis: a diagnostic dilemma: case report," The Indian Journal of Tuberculosis, vol. 53, p. 27, 2006.

[5] A. A. Berg, "Transverse ectopy of the testis," Annals of Surgery, vol. 40, pp. 223-224, 1904.

[6] T. Kimura, "Transverse ectopy of the testis with masculine uterus," Annals of Surgery, vol. 68, no. 4, pp. 420-425, 1918.

[7] R. L. Gupta and P. Das, "Ectopia testis transversa," Journal of the Indian Medical Association, vol. 16, no. 35, pp. 547-549, 1960.

[8] J. K. Chacko, P. D. Furness III, and G. C. Mingin, "Presentation of fused vas deferens," Urology, vol. 67, no. 5, pp. 1085.e17-1085.e18, 2006.

[9] H. L. Frey and J. Rajfer, "Role of the gubernaculum and intraabdominal pressure in the process of testicular descent," The Journal of Urology, vol. 131, no. 3, pp. 574-579, 1984.

[10] C. G. Thevathasan, "Transverse ectopia of the testis," The Australian and New Zealand Journal of Surgery, vol. 37, no. 2, pp. 93-102, 1967.

[11] A. Inugala, "Tranverse testicular ectopia with persistent Müllerian duct syndrome and inginal hernia - a case report," Asian Journal of Case Reports in Surgery, vol. 5, no. 3, pp. 10-14, 2020.

[12] S. Barrack, "Crossed testicular ectopia with fused bilateral duplication of the vasa deferential: an unusual finding in crytochidism," East African Medical Journal, vol. 71, no. 6, p. 398, 1994.

[13] P. Kajal, K. N. Rattan, N. Bhutani, and V. Sangwan, "Transverse testicular ectopia with scrotal hypospadias but without inguinal hernia - case report of a rare association," International Journal of Surgery Case Reports, vol. 31, pp. 167-169, 2017.
[14] M. W. L. Gauderer, E. R. Grisoni, T. A. Stellato, J. L. Ponsky, and R. J. Izant Jr., "Transverse testicular ectopia," Journal of Pediatric Surgery, vol. 17, no. 1, pp. 43-47, 1982.

[15] T. F. Kolon, C. D. A. Herndon, L. A. Baker et al., "Evaluation and treatment of cryptorchidism: AUA guideline," The Journal of Urology, vol. 192, no. 2, pp. 337-345, 2014.

[16] C. Sommer, E. Stathopoulos, M. C. Antoniou, K. Busiah, M. Hauschild, and O. Sanchez, "An empty hemiscrotum: transverse testicular ectopia," Journal of Pediatric Surgery Case Reports, vol. 59, p. 101532, 2020.

[17] W. W. Lam, S. D. Le, L. Chan, F. L. Chan, and P. K. Tam, "Transverse testicular ectopia detected by MR imaging and MR venography," Pediatric Radiology, vol. 32, no. 2, pp. 126129, 2002.

[18] C. Gkekas, E. N. Symeonidis, I. Tsifountoudis et al., "A Rare Variation of Transverse Testicular Ectopia (TTE) in a Young Adult as an Incidental Finding during Investigation for Testicular Pain," Case Reports in Urology, vol. 2018, 4 pages.

[19] F. Berkmen, "Persistent Mullerian duct syndrome with or without transverse testicular ectopia and testis tumours," British Journal of Urology, vol. 79, no. 1, pp. 122-126, 1997.

[20] B. Erginel, S. Bilici, Ş. Gedik et al., "Crossed testicular ectopia: report of six cases," African Journal of Paediatric Surgery, vol. 11, no. 3, pp. 269-272, 2014.

[21] R. Bascuna Jr., J. Y. Ha, Y. S. Lee, H. Y. Lee, Y. J. Im, and S. W. Han, "Transverse testis ectopia: diagnostic and management algorithm," International Journal of Urology, vol. 22, no. 3, pp. 330-331, 2015.

[22] V. Raj, R. G. Redkar, S. Krishna, and S. Tewari, "Rare case of transverse testicular ectopia - case report and review of literature," International Journal of Surgery Case Reports, vol. 41, pp. 407-410, 2017.

[23] K. Evans and A. Desai, "Total laparoscopic correction of transverse testicular ectopia," Journal of Pediatric Urology, vol. 4, no. 3, pp. 245-246, 2008.

[24] R. S. Kamble, R. K. Gupta, A. R. Gupta, P. R. Kothari, K. V. Dikshit, and K. K. Kesan, "Laparoscopic management of transverse testicular ectopia with persistent Müllerian duct syndrome," Journal of Minimal Access Surgery, vol. 11, no. 3, pp. 213-215, 2015. 